\title{
The Efficacy of 1\% Chlorhexidine Gel on the Reduction of Dry Socket Occurence Following Surgical Third Molar Extraction- Pilot Study
}

\author{
Jehona Ahmedi', Enis Ahmedi², Zana Agani'1, Vjosa Hamiti', Bylbyl Reçica1, \\ Arlinda Tmava-Dragusha ${ }^{2}$ \\ ${ }^{1}$ Department of Oral Surgery, University Dental Clinical Center of Kosova, Prishtina, Kosovo \\ ${ }^{2}$ Department of Prosthodontists, University Dental Clinical Center of Kosova, Prishtina, Kosovo \\ Email: jehona.ahmedi@hotmail.com
}

Received 13 January 2014; revised 17 February 2014; accepted 25 February 2014

Copyright (C) 2014 by authors and Scientific Research Publishing Inc.

This work is licensed under the Creative Commons Attribution International License (CC BY). http://creativecommons.org/licenses/by/4.0/

(c) (i) Open Access

\begin{abstract}
Aim \& Objectives: The aim of this prospective pilot-study was to assess the efficacy of intra alveolar application of $1 \%$ chlorhexidine gel (CHX) on the reduction of dry socket (DS) occurrence following surgical extraction of mandibular third molars. Materials and Methods: A randomized split-mouth-design study included twenty-five patients with bilaterally impacted lower third molars (partial or full bone) requiring full thickness mucoperiastal flap reflection for extraction. Following surgical extraction of third lower molar, $2 \mathrm{ml}$ of gel containing $1 \%$ chlorhexidine digluconate (Chlorhexamed ${ }^{\circledR}$ Gel 1\%) were placed in the experimental side, and saline solution was used for irrigation in the control side of extraction sockets, both followed by suturing of extraction site. The surgeries and follow up examinations were performed by the same surgeon. The follow up visits were performed at 48 hours and on day seven, post surgery where presence or absence of dry socket using the Blum criteria for diagnosis was evaluated and pain intensity by Visual Analogue Scale (VAS) 0 - 100 was observed. Results: In this pilot study, dry socket was present in 4.0 and $\mathbf{2 8 . 0 \%}$ of cases in the experimental and control groups, respectively $(P=0.048)$. Fisher's test revealed a statistically significant reduction of dry socket occurrence following the use of $1 \%$ CHX gel versus saline solution. Conclusion: The application of CHX gel $1 \%$ may significantly reduce the incidence of DS following third molar extraction. Prophylactic use of CHX gel 1\% may be suggested in all patients, especially in the patients at risk of development of DS.
\end{abstract}

\section{Keywords}

Dry Socket; Chlorhexidine 1\%; Third Molar Surgery

How to cite this paper: Ahmedi, J., et al. (2014) The Efficacy of 1\% Chlorhexidine Gel on the Reduction of Dry Socket Occurence Following Surgical Third Molar Extraction-Pilot Study. Open Journal of Stomatology, 4, 152-160.

http://dx.doi.org/10.4236/ojst.2014.43023 


\section{Introduction}

Dry socket (DS) is the most common and very unpleasant complication which occurs after permanent tooth extraction [1] [2]. Studies report the incidence of dry socket from 1.0\% - 4.0\% after tooth extraction, with higher incidence in surgical extraction of mandibular third molars between 5.0\% - 30.0\% [3]-[5]. Blum defined dry socket as "postoperative pain in and around the extraction wound which increases in intensity between the first and third day after tooth extraction accompanied by partially or completely disintegrated blood clot within the alveolar socket with or without halitosis” [6]. Birn, explained the pathogenesis of the dry socket through fibrinolytic activity. Higher frequency of DS following third molar extraction is explained by two main local reasons, trauma and bacterial contamination of the tooth socket during or immediately after tooth extraction [3] [7] [8]. These conditions cause inflammation of the alveolar bone releasing the tissue activator, which in turn converts the plasminogen to plasmin in the blood clot that releases the kinins from kininogen, responible for the pain. The outcome of the latter is a disintegrated blood clot and pain [6]. Goldstein et al. have shown that bacterial endotoxins are able to induce fibrinolytic activity from human leucocytes and in turn to dissolve the blood clot [7].

Amler, studied 11 biopsy specimens from the alveoli of the patients diagnosed as dry socket, taken in intervals from third day through ninth day postoperatively and concluded that alveolar osteitis appears as a result of healing disruption between clot formation and granulation tissue formation [9].

Overall, the exact mechanism of the development of DS is not known and several research attempts to reduce the incidence of dry socket utilizing different intra alveolar dressings or different systemic medications (e.g. antibiotics) following surgical tooth extractions, have been made.

Chlorhexidine (CHX) solution has been shown to have a higher antimicrobial effect than other antiseptics used in oral cavity for various clinical situations. Preoperative mouth rinse with CHX has been shown to reduce dry socket occurrence by 45\% - 80\% [10]. Recently, CHX has been introduced as 1\% bioadhesive gel increasing the chance for reducing dry socket occurrence due to higher concentration opposed to $0.12 \%$ and $0.2 \% \mathrm{CHX}$ preparations. The objective of our study was to determine the effect of $1 \% \mathrm{CHX}$ gel compared to a control group (irrigated with saline solution) on reducing the incidence of dry socket after bilateral surgical extraction of third molars.

\section{Material and Methods}

This study was conducted at the Department of Oral Surgery, University Dental Clinical Center of Kosova, during the period of June 2013 through October 2013. A randomized split-mouth-design study included twentyeight patients meeting the inclusion criteria. The surgery consisted on bilateral surgical extraction of lower third molars with two weeks spacing between the two surgeries. The research protocol had been approved by the local Committee of Ethics. All patients were asked to read and sign an informed consent to be included in the study.

\subsection{Inclusion Criteria}

Patients of both genders aged between 18 through 30 years old with bilateral partially or fully impacted lower third molars in similar position as shown in Figure 1, indicated for surgical extraction.

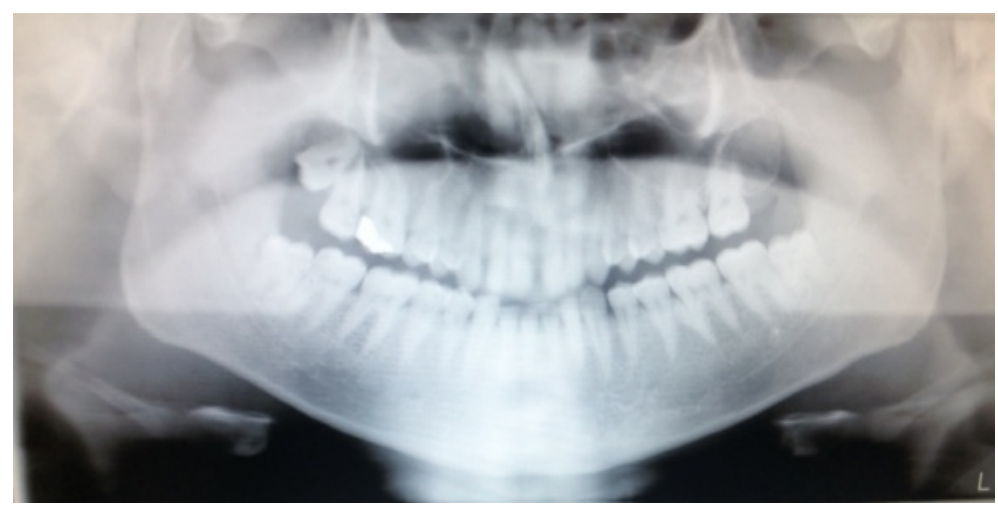

Figure 1. Ortopanthomography. 


\subsection{Exclusion Criteria}

Patients with systemic illness, smokers and patients, who were taking any medication or oral contraceptives, were excluded in order to eliminate the possibility of interferences with surgery outcome. Patients with acute infection, and acute pericoronitis, or those using antibiotics or requiring antibiotics 10 days prior to surgery, were excluded. The aim of the research was to investigate the effect of CHX in the incidence of DS, eliminating the possibility for interference of any predisposing factor in the development of DS.

\subsection{The Surgical Procedure}

All patients were asked to read and sign an informed consent to be included in the study. Randomization was used to determine which side will be a control side and the other experimental side. All the surgeries and follow up visits were performed by the same operating oral surgeon. Surgery was performed in the operating theater following the standard infection control guidelines for surgery using $1 \%$ and $10 \%$ betadine for intra- and extraoral surgical field disinfection, respectively, and covered with sterile surgical drapes. Appropriate local analgesia was secured for all surgeries using $4 \mathrm{ml}$ of $2 \%$ Lidocaine) with 1:800,000 Adrenaline (Alkaloid, Skopje) to give Inferior Alveolar Nerve Block (IANB) injections. Standard bilateral third molar extraction technique was used with triangular flap method. The incision line originated at the distobuccal angle of the second molar, at the gingival margin, continuing distally along the alveolar ridge, behind the third molar and a vertical release incision starting from distobucal angle of second molar to the vestibule as shown in Figure 2.

Full thickness buccal flap was raised using an elevator for anterior-posterior bone exposure. If needed bone osteotomy was performed with an electrical handpiece using a number 3 tungsten carbide bur. When necessary, prior to extraction, dental sectioning was carried out using fissural tungsten 1702 carbide bur with the same handpiece as shown on Figures 3 and 4.

In addition after tooth extraction alveolar edges were smoothed and thorough curettage and debridment was performed. Two milliliters of $1 \%$ chlorhexidine digluconate gel (Chlorhexamed 1\%) were placed in the tooth socket, followed by suturing with 3/0 (Ethicon Vicryl, 3/0 absorbable suture, $19 \mathrm{~mm}$ rev cut 3/8, $45 \mathrm{~cm}$ ) silk suturing material as shown in Figures 5-8.

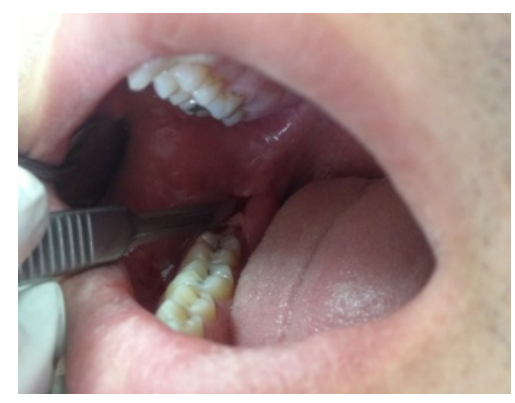

Figure 2. Incision line.

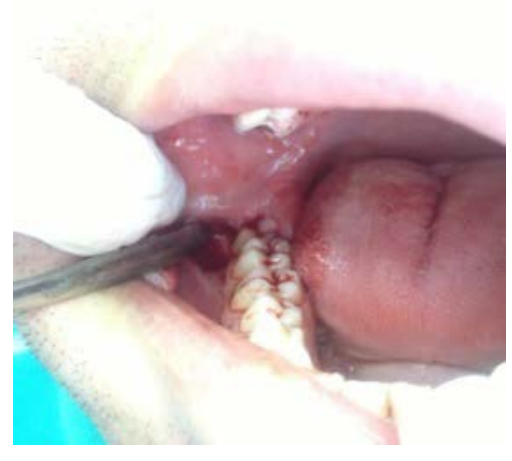

Figure 3. Elevating full thickness flap. 


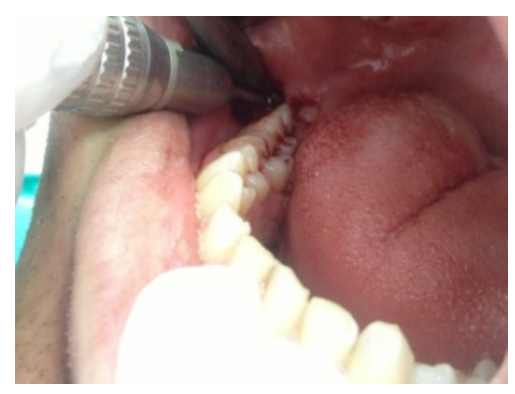

Figure 4. Osteotomy.

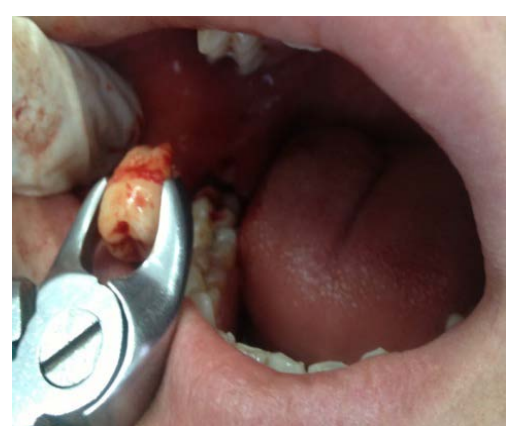

Figure 5. Tooth extraction.

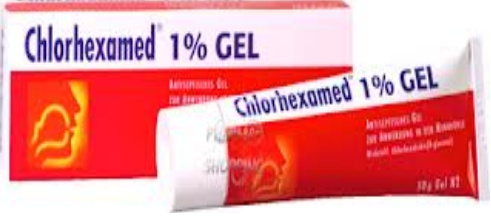

Figure 6. Chlorhexamed.

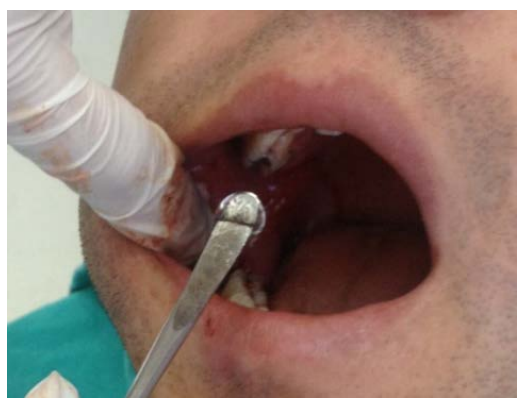

Figure 7. Aplication of chlorhexamedgel.

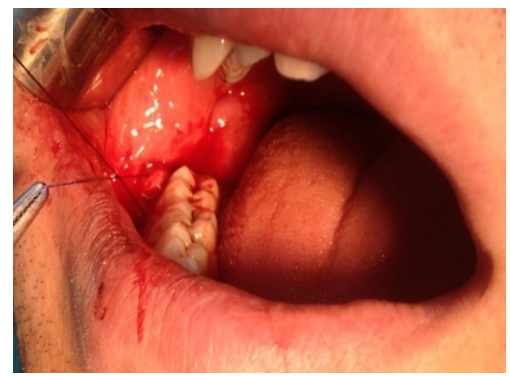

Figure 8. Suturing. 
Two weeks later, mandibular third molar extraction was performed on the control side to the same patients with modified surgical protocol towards the end procedure, following the extraction. It consisted of a gentle curettage and irrigation with $5 \mathrm{ml}$ of sterile saline solution of the tooth socket followed by suturing with 3/0 silk suturing material.

Four hundred milligrams of ibuprofen were proscribed postoperatively to patients if needed for pain control. The patient was given the usual postoperative instructions. Follow up visits were timed at 48 hours to check and record any dry socket and pain symptoms and at day seven for suture removal.

The other visits before the schedule were timed to suit individual needs of patients (pain/dry socket). Positive diagnosis of dry socket was made on the basis of clinical and subjective findings. The clinical findings included evidence of one or more of the following: 1) absence of a clot, 2) necrosis of a blood clot, and 3) exposed bone and was recorded as Yes or No. Subjective findings included reports of persistent or increasing postoperative pain after the surgery with throbbing pain at the surgical site not relieved by mild analgesics. Data analysis was performed using the Fisher's exact test.

Pain was assessed by VAS, as shown in Figure 9.

Positive cases for dry socket were treated by irrigation with saline solution and placing Alvogyl paste (Septodont) in the tooth socket, as shown in Figure 10.

\section{Results}

Unpaired T-test was used for parametric values and chi-square test, Fischer's test and Man Whitney tests were applied for the comparison of frequencies. The difference was significant if $\mathrm{P}<0.05$.

Fisher's test revealed statistically significant reduction in dry socket occurrence in the study group (1\% CHX gel) versus the experimental group (sterile saline). Dry socket occurred in $4.0 \%$ of cases in the experimental group and in $28.0 \%$ of cases in the control group $(\mathrm{P}=0.048)$. Compared to study group, the control group was double the risk for DS occurrence $(\mathrm{RR}=2.04,95 \% \mathrm{CI} 1.31$ - 3.15), as shown in Table 1 .

Significant differences in appearance of DS were found between partially and fully impacted teeth. Extracted fully impacted teeth shown a higher incidence for DS after the surgery in both groups of research as shown in Table 2.

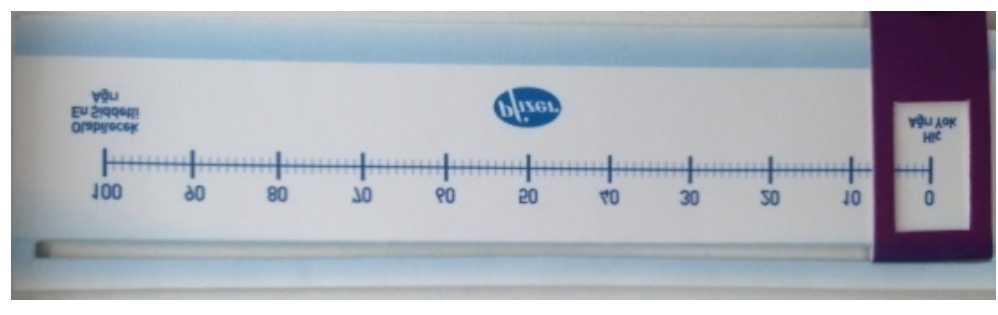

0 - 10 no pain; 10 - 30 mild pain; 30 - 60 moderate pain; 60 - 100 severe pain.

Figure 9. Visual analogue scale.

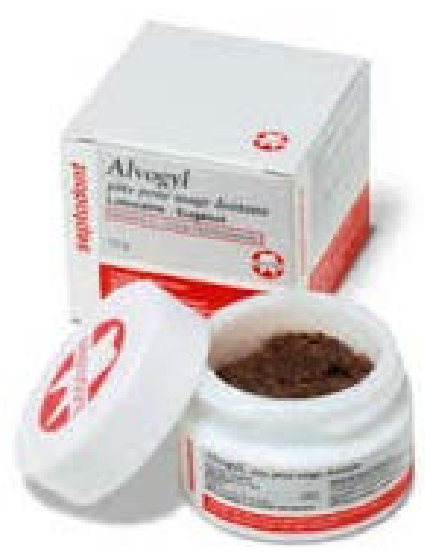

Figure 10. Alvogyl paste. 
Table 1. Incidence of dry socket.

\begin{tabular}{ccccccc}
\hline \multirow{2}{*}{ Dry socket } & \multicolumn{2}{c}{ Study group } & \multicolumn{2}{c}{ Control group } & \multicolumn{2}{c}{ Total } \\
\cline { 2 - 6 } & $\mathrm{N}$ & $\%$ & $\mathrm{~N}$ & $\%$ & $\mathrm{~N}$ & $\%$ \\
\hline No & 24 & 96.0 & 18 & 72.0 & 42 & 84.0 \\
Yes & 1 & 4.0 & 7 & 28.0 & 8 & 16.0 \\
Total & $\mathbf{2 5}$ & $\mathbf{1 0 0 . 0}$ & $\mathbf{2 5}$ & $\mathbf{1 0 0 . 0}$ & $\mathbf{5 0}$ & $\mathbf{1 0 0 . 0}$ \\
Fisher test & \multicolumn{2}{c}{$\mathrm{P}=0.048, \mathrm{RR}=2.04(95 \% \mathrm{CI} 1.31-3.15)$} \\
\hline
\end{tabular}

Table 2. Incidence of dry socket based on impaction of lower third molar.

\begin{tabular}{cccccc}
\hline \multirow{3}{*}{ DS } & & \multicolumn{2}{c}{ Partially impacted } & \multicolumn{2}{c}{ Fully impacted } \\
\cline { 3 - 6 } & & $\mathbf{N}$ & $\mathbf{\%}$ & $\mathbf{N}$ & \% \\
\hline \multirow{3}{*}{ Study group } & Yes & - & - & 1 & 11.2 \\
& No & 16 & 100.0 & 8 & 88.8 \\
& Total & 16 & 100.0 & 9 & 100.0 \\
\multirow{3}{*}{ Control group } & Yes & 3 & 18.8 & 4 & 44.4 \\
& No & 13 & 81.2 & 5 & 55.6 \\
& Total & 16 & 100.0 & 9 & 100.0 \\
\multirow{2}{*}{ Total } & Yes & 3 & 9.4 & 5 & 27.8 \\
& No & 29 & 90.6 & 13 & 72.2 \\
& Total & 32 & 100.0 & 18 & 100.0 \\
\hline
\end{tabular}

Incidence of DS was higher in surgeries requiring osteotomies during the tooth extraction 52.9\% compare to surgeries without osteotomy 25.0\%. In all cases incidence of DS was representative in higher values in the control groups Table 3.

According to indication for removal of third lower molar frequency of DS was higher 29.2\% in pericoronitis cases versus $4.5 \%$ in orthodontic cases. In cases where tooth decay was the indication for extraction, no case of dry socket was noted. In total, the incidence of DS occurrence was higher in the control group, as shown in Table 4.

Forty eight hours post surgery there were statistically different mean values of VAS for the experimental group 23.6 ( $\mathrm{SD} \pm 16.0$ ), range 0 - 60 and for the control group 55.6 ( $\mathrm{SD} \pm 25.0$ ), range $0-90$, ( $\mathrm{P}<0.0001$ ). Mann Whitney testing revealed statistical significance of the groups for VAS values at 48 hours post surgery (U' = 527.0, $\mathrm{P}<0.0001$ ), as shown in Table 5 .

Seven days post surgery, mean value for VAS was 10.8 (SD \pm 16.6 ), range 0 - 60 for the study (CHX) group versus 26.4 ( $\mathrm{SD} \pm 16.3$ ), range 0 - 60 for the control group that was statistically significant $(\mathrm{P}=0.0008)$ Table 6.

\section{Discussion}

Although the exact mechanism and etiology of DS remains unknown, researchers attempt to explain that many factors are implicated in development of DS, age, gender, smoking, oral contraceptives, infection and trauma during the surgery [2] [11]-[13]. Trauma and infection remain the most influential local factors in development of DS after surgical lower third molar extraction [3] [6] [14]. The results of this pilot-study show the higher prevalence of DS along with increase in extraction difficulty. The difference in the prevalence of DS between cases of extracted teeth required osteotomy (52.9\%) and extracted lower third molars without osteotomy (25.0\%) was statistically significant. The obtain findings are in accordance with attitudes of many researchers and it support the datas in the literature in which trauma is a one of main local reasons in pathogenesis of dry socket. The literature reports different techniques and medicaments that have been and still are being investigated. These includes antitibacterial agents, antiseptic agents, antifibrinolytic agents, clot support agents and more [3]. CHX is a bactericidal agent with broad antibacterial spectrum. It's safety for use in medicine with no adverse effects and not responding with bacterial resistance in human organisms are some of advantages of it's use compare to the systemic antibiotics. NB Duvall, in his comparative in vivo study for bacteriemia after third mo- 
Tabela 3. Incidence of dry socket according to type (difficulty) of surgery and groups.

\begin{tabular}{|c|c|c|c|c|c|c|c|}
\hline \multirow{2}{*}{\multicolumn{2}{|c|}{ Dry socket }} & \multicolumn{6}{|c|}{ Type of surgery } \\
\hline & & \multicolumn{2}{|c|}{ Without osteotomy } & \multicolumn{2}{|c|}{ Osteotomy } & \multicolumn{2}{|c|}{ Osteotomy and odontosection } \\
\hline & & $\mathbf{N}$ & $\%$ & $\mathbf{N}$ & $\%$ & $\mathbf{N}$ & $\%$ \\
\hline \multirow{3}{*}{ Study group } & Yes & - & - & 1 & 5.6 & - & - \\
\hline & No & 5 & 100.0 & 17 & 94.4 & 2 & 100.0 \\
\hline & Total & 5 & 100.0 & 18 & 100.0 & 2 & 100.0 \\
\hline \multirow{3}{*}{ Control group } & Yes & 3 & 42.9 & 3 & 18.8 & 1 & 50.0 \\
\hline & No & 4 & 57.1 & 13 & 81.3 & 1 & 50.0 \\
\hline & Total & 7 & 100.0 & 16 & 100.0 & 2 & 100.0 \\
\hline \multirow{3}{*}{ Total } & Yes & 3 & 25.0 & 18 & 52.9 & 1 & 25.0 \\
\hline & No & 9 & 75.0 & 30 & 88.2 & 3 & 75.0 \\
\hline & Total & 12 & 100.0 & 34 & 100.0 & 4 & 100.0 \\
\hline
\end{tabular}

Table 4. Dry socket incidence according to indication for extraction and groups.

\begin{tabular}{|c|c|c|c|c|c|c|c|}
\hline \multirow{2}{*}{\multicolumn{2}{|c|}{ Dry socket }} & \multicolumn{6}{|c|}{ Indication for extraction } \\
\hline & & \multicolumn{2}{|c|}{ Caries } & \multicolumn{2}{|c|}{ Orthodontic indication } & \multicolumn{2}{|c|}{ Chronic pericoronitis } \\
\hline & & $\mathbf{N}$ & $\%$ & $\mathbf{N}$ & $\%$ & $\mathbf{N}$ & $\%$ \\
\hline \multirow{3}{*}{ Study group } & Yes & - & - & - & - & 1 & 8.3 \\
\hline & No & 2 & 100.0 & 11 & 100.0 & 11 & 91.7 \\
\hline & Total & 2 & 100.0 & 11 & 100.0 & 12 & 100.0 \\
\hline \multirow{3}{*}{ Control group } & Yes & - & - & 1 & 9.1 & 6 & 50.0 \\
\hline & No & 2 & 100.0 & 10 & 90.9 & 6 & 50.0 \\
\hline & Total & 2 & 100.0 & 11 & 100.0 & 12 & 100.0 \\
\hline \multirow{3}{*}{ Total } & Yes & - & - & 1 & 4.5 & 7 & 29.2 \\
\hline & No & 4 & 100.0 & 21 & 95.5 & 17 & 70.8 \\
\hline & Total & 4 & 100.0 & 22 & 100.0 & 24 & 100.0 \\
\hline
\end{tabular}

Table 5. VAS $48 \mathrm{hr}$ after the surgery.

\begin{tabular}{|c|c|c|c|c|}
\hline \multirow{2}{*}{ VAS $48 \mathrm{hr}$} & \multirow{2}{*}{$\begin{array}{l}\mathbf{E} \\
\mathrm{N}\end{array}$} & \multirow{2}{*}{$\begin{array}{c}\text { Group } \\
\%\end{array}$} & \multicolumn{2}{|c|}{ Control group } \\
\hline & & & $\mathrm{N}$ & $\%$ \\
\hline $0-10$ & 8 & 32.0 & 1 & 4.0 \\
\hline $20-30$ & 10 & 40.0 & 5 & 20.0 \\
\hline $40-50$ & 6 & 24.0 & 4 & 16.0 \\
\hline $60-70$ & 1 & 4.0 & 7 & 28.0 \\
\hline $80-90$ & - & - & 8 & 32.0 \\
\hline Total & 25 & 100.0 & 25 & 100.0 \\
\hline Mean & & & & \\
\hline DS & & & & \\
\hline Min & & & & \\
\hline Max & & & & \\
\hline Mann Whitney test & & & & \\
\hline
\end{tabular}

lar extraction in first group using amoxycilin 2 gr and in second group using CHX mouthwash $0.2 \%$ found no statistically significant difference between groups. This increase the possibility of its use in antibacterial prevention compared with the use of systemic antibiotics [12]. Haraji et al in their study which includes 80 patients with bilaterally third molar extraction using $\mathrm{CHX}$ gel $0.2 \%$ packed to the crest of the alveolar ridge with gelatin sponge, found reduction of dry socket incidence from $32.6 \%$ to $11.3 \%$. Besides decreasing the incidence of dry socket, using CHX gel, they also found reducing of postsurgical pain [13]. Chew B. in their study investigate the effect of chlorhexidine mouthwash in pain after third molar extraction. Significant differences were shown in the pain score and the number of inflammation sites [15]. In our study the mean value of VAS $48 \mathrm{hr}$ after the surgery in CHX group, 23.6 was lower compare with control group 55.6 which support the above mentioned research. Caso et al. published a meta-analysis of CHX solution, its use intra-operatively and 7 days postopera- 
Table 6. Parameters of pain 7 days after surgical extraction.

\begin{tabular}{|c|c|c|c|c|}
\hline \multirow{2}{*}{ VAS } & \multicolumn{2}{|c|}{ Experimental group } & \multicolumn{2}{|c|}{ Control group } \\
\hline & $\mathrm{N}$ & $\%$ & $\mathrm{~N}$ & $\%$ \\
\hline $0-10$ & 20 & 80.0 & 5 & 20.0 \\
\hline $20-30$ & 1 & 4.0 & 13 & 52.0 \\
\hline $40-50$ & 3 & 12.0 & 6 & 24.0 \\
\hline $60-70$ & 1 & 4.0 & 1 & 4.0 \\
\hline Total & 25 & 100.0 & 25 & 100.0 \\
\hline Mean & \multicolumn{2}{|c|}{10.8} & \multicolumn{2}{|c|}{26.4} \\
\hline DS & \multicolumn{2}{|c|}{16.6} & \multicolumn{2}{|c|}{16.3} \\
\hline Min & \multicolumn{2}{|c|}{0} & \multicolumn{2}{|c|}{0} \\
\hline Max & \multicolumn{2}{|c|}{60} & \multicolumn{2}{|c|}{60} \\
\hline Mann Whitney test & \multicolumn{4}{|c|}{$U^{\prime}=485.5, P=0.0008$} \\
\hline
\end{tabular}

tively and appears to reduce the frequency of DS following surgical removal of lower third molars [16]. Torres et al. evaluate the effects of CHX gel and reports that one application of $0.2 \% \mathrm{CHX}$ bioadhesive gelpost-extraction in the alveola reduced the incidence of DS. The appearance of DS was $30.76 \%$ in control group opposite to 17.64\% in CHX group [17]. Iglesias at al. observed some degree of effectiveness of chlorhexidine gel compared to chlorhexidine mouthwash and found $7.5 \%$ incidence of dry socket in gel group (0.25 CHX) and $25 \%$ in the chlorhexidine mouthwash treated group (0.12\% CHX), after surgical extraction of third molars [18].

\section{Conclusion}

The use of 1\% chlorhexidine gel has shown promising results in the reduction of dry socket occurrence following surgical extraction of the third molars provided some preconditions are met. However, further research and large samples are required to establish the best treatment practices to prevent this highly uncomfortable post extraction complication.

\section{References}

[1] Osborn, T.P., Frederickson Jr., G., Small, I.A. and Torgerson, T.S. (1985) A Prospective Study of Complications Related to Mandibular Third Molar Surgery. Journal of Oral and Maxillofacial Surgery, 43, 767-769. http://dx.doi.org/10.1016/0278-2391(85)90331-3

[2] Fridrich, K.L. and Olson, R.A.J. (1990) Alveolar Osteitis Following Removal of Mandibular Third Molars. Anesthesia Progress, 37, 32-41.

[3] Birn, H. (1973) Etiology and Pathogenesis of Fibrinolytic Alveolitis (Dry Socket). IJOS, 2, 211-263.

[4] Amler, M.H. (1973) Pathogenesis of Disturbed Extraction Wounds. IJOS, 31, 666-674.

[5] Noroozi, A.R. and Philbert, R.F. (2009) Modern Concepts in Understanding and Management of the "Dry Socket" Syndrome: Comprehensive Review of the Literature. Oral Surgery, Oral Medicine, Oral Pathology, Oral Radiology, and Endodontology, 107, 30-35. http://dx.doi.org/10.1016/j.tripleo.2008.05.043

[6] Blum, I. (2002) Contemporary Views on Dry Socket. A Critical Review. IJOS, 31, 309-317.

[7] Goldstein, I.M., Wünschmann, B., Astrup, T. and Henderson, E.S. (1971) Effects of Bacterial Endotoxin on the Fibrinolytic Activity of Normal Human Leukocytes. Blood Journal, 37, 447-453.

[8] Wong, J.D. (1993) Alveolar Osteitis: A Review. University of Sydney.

[9] Hermesch, C.B., et al. (1998) Perioperative Use of 0.12\% Chlorhexidine Gluconate for the Prevention of Alveolar Osteitis. Efficacy and Risk Factor Analysis. Oral Surgery, Oral Medicine, Oral Pathology, Oral Radiology, and Endodontology, 85, 381-387. http://dx.doi.org/10.1016/S1079-2104(98)90061-0

[10] Lagares, D.T., Cossio, P.I., Perez, J.L.G., Romero Ruiz, M.M., Calderon, M.C. and Figallo, M.A.S. (2006) Intra-Alveolar Chlorhexidine Gel for the Prevention of Dry Socket in Mandibular Third Molar Surgery. A Pilot Study. Medicina Oral Patologia Oral y Cirugia Bucal, 11, 179-184.

[11] Piecuch, J.F. (2012) What Strategies Are Helpful in the Operative Management of Third Molars? Journal of Oral and Maxillofacial Surgery, 70, S25-S32. http://dx.doi.org/10.1016/j.joms.2012.04.027

[12] Duvall, N.B., Fisher, T.D., Hensley, D., Hancock, R.H. and Vandewalle, K.S. (2013) The Comparative Efficacy of 
0.12\% Chlorhexidine and Amoxicillin to Reduce the Incidence and Magnitude of Bacteremia during Third Molar Extractions: A Prospective, Blind, Randomized Clinical Trial. Oral Surgery, Oral Medicine, Oral Pathology, Oral Radiology, and Endodontology, 115, 752-763. http://dx.doi.org/10.1016/j.0000.2012.11.019

[13] Haraji, A., Rakhshan, V., Khamverdi, N. and Alishahi, H.K. (2013) Effects of Intra-Alveolar Placement of 0.2\% Chlorhexidine Bioadhesive Gel on Dry Socket Incidence and Postsurgical Pain: A Double-Blind Split-Mouth Randomized Controlled Clinical Trial. Journal of Orofacial Pain, 27, 256-262. http://dx.doi.org/10.11607/jop.1142

[14] MacGregor, A.J. (1969) Aetiology of Dry Socket: A Clinical Investigation. British Journal of Oral Surgery, 6, 49-58. http://dx.doi.org/10.1016/S0007-117X(68)80026-5

[15] Chew, B., Cheng, W.L., Tay, S. and Fei, Y.J. (2007) Comparison of Two Commercially Available Mouth Rinses on Gingival Inflammation, Pain and Acceptability after Third Molar Surgery. Singapore Dental Journal, 29, 34-40.

[16] Caso, A., Hung, L.K. and Beirne, O.R. (2005) Prevention of Alveolar Osteitis with Chlorhexidine: A Meta-Analytic Review. Oral Surgery, Oral Medicine, Oral Pathology, Oral Radiology, and Endodontology, 99, 155-159. http://dx.doi.org/10.1016/j.tripleo.2004.05.009

[17] Torres-Lagares, D., Infante-Cossio, P., Gutierrez-Perez, J.L., Romero-Ruiz, M.M., Garcia-Calderon, M. and SerreraFigallo, M.A. (2006) Intra-Alveolar Chlorhexidine Gel for the Prevention of Dry Socket in Mandibular Third Molar Surgery. A Pilot Study. Medicina Oral Patologia Oral y Cirugia Bucal, 11, E179-E184.

[18] Hita-Iglesias, P., Torres-Lagares, D., Flores-Ruiz, R., Magallanes-Abad, N., Basallote-Gonzalez, M. and GutierrezPerez, J.L. (2008) Effectiveness of Chlorhexidine Gel versus Chlorhexidine Rinse in Reducing Alveolar Osteitis in Mandibular Third Molar Surgery. Journal of Oral and Maxillofacial Surgery, 66, 441-445. http://dx.doi.org/10.1016/j.joms.2007.06.641 